\title{
Adapting Peer Review to an Online Course: An Exploratory Case Study
}

\author{
Linda V. Knight and Theresa A. Steinbach \\ DePaul University, Chicago, Illinois, USA
}

\section{Iknight@cdm.depaul.edu; tsteinbach@cdm.dpaul.edu \\ Executive Summary}

With demonstrated benefits to higher level learning, peer review in the classroom has been well researched and popular since at least the 1990s. However, little or no prior studies exist into the peer review process for online courses. Further, we found no prior research specifically addressing the operational aspects of online peer review. This research addresses that gap by comparing the issues involved in managing peer review for an online course with those for a traditional classroom course. In an exploratory case study, two sections of the same introductory level course were taught by the same professor in the same academic term, one section in the traditional classroom and one as an online section. Both sections covered the same material in the same order. Online students had access to narrated PowerPoint recordings that tracked in-class lectures. The same assignments and exams were used. The two sections used a joint discussion board for posting questions and answers about the course material. In short, the two courses were almost identical, except for the steps necessary to make peer review operate in an online environment.

An eleven-step process for implementing peer review was isolated and documented as part of this research. All steps except the first, creating the grading rubric, required more time and effort for an online class than for a traditional class. Four steps were substantially more complex in an online environment: assigning students to do specific peer reviews; handling late reviews; hiding reviewer identity before making reviews available to reviewees; and distributing completed peer reviews back to reviewees. Overall, results suggest that, without specialized supporting software, electronic reviews for an online class are far more complex to orchestrate than similar reviews administered using paper in a traditional classroom. Minor procedural steps that easily are made both unambiguous and obligatory in a paper-based classroom peer review became far more difficult to implement online. In addition, since specific peer review software is seldom available, the need to use a variety of software products, each of which was originally designed for other purposes, added substantially to the intricacy of implementing online peer review.

This research provides specific suggestions for faculty considering using peer reviews in online

Material published as part of this publication, either on-line or in print, is copyrighted by the Informing Science Institute. Permission to make digital or paper copy of part or all of these works for personal or classroom use is granted without fee provided that the copies are not made or distributed for profit or commercial advantage AND that copies 1) bear this notice in full and 2) give the full citation on the first page. It is permissible to abstract these works so long as credit is given. To copy in all other cases or to republish or to post on a server or to redistribute to lists requires specific permission and payment of a fee. Contact Publisher@InformingScience.org to request redistribution permission. courses, particularly in online Information Technology courses or other courses where writing is not the primary activity being reviewed. In addition, the online peer review features and functionality detailed here provide a basic requirements definition for a potential peer review software package flexible enough to be used across disciplines and with both traditional and online classes. 
Keywords: peer review, online course, online teaching, online learning, online education, HTML

\section{Introduction}

This article presents the results of an exploratory case study into one adaptation of peer review for an online course environment. Peer review can be defined as the process where one's colleagues review one's work product. This process can take place within a workplace as part of employee assessment or between academic colleagues evaluating a scholarly paper. For purposes of this research, peer review is described within the context of educational use. Specifically, we consider how the peer review process was modified when one traditional classroom course was made available in a totally online environment. We look specifically at what was effective and ineffective from an instructor standpoint.

Numerous studies of the educational use of peer review have been conducted, many of them detailed in the Background section of this paper. These prior studies, conducted primarily during the 1990s, led to peer review's wide acceptance as a teaching practice in classrooms around the world. While a variety of techniques have been described for implementing peer review, we are aware of no prior studies that have addressed peer review in an online course environment. Yet, it is not reasonable to assume that the processes used to conduct peer reviews in the classroom can simply be transferred to an online course.

We believe this paper represents the first research to investigate the mechanics of incorporating peer review in an online course. We address this issue by considering two class sections, one held in a traditional classroom and the other an online version of the same course. Both sections were taught by the same professor during the same academic term. By comparing the mechanics of peer review in these two environments, we provide insights into the unique challenges of peer review for online courses.

In the Background section of this paper, we outline the established benefits of peer review in education, document the traditional mechanics of its implementation, and cite some of its more common academic uses. In the Study Context section, we present background information on the university, students, and course involved in this research. We also describe the traditional role of peer review in the course that is the subject of this study. In the Requirements section, we describe our goals for an online peer review process. The Method section then describes the processes we went through in attempting to meet these goals. The Analysis of Results section evaluates the effectiveness of our solution in terms of our original goals and also compares the online solution to how peer review is handled in a traditional classroom section of the same course. The Discussion section provides insights into some of the greatest hurdles to implementing peer review in online courses. Finally, in the concluding section we offer suggestions for other professors implementing online peer review, address whether peer review is worth implementing in an online course, and assess the potential for future software support.

\section{Background}

Peer review can be a grading tool, an assessment tool, or a learning tool (Wessa \& De Rycker, 2010). However, most prior research speaks of peer review primarily in terms of its learning value. Peer review is often cited as a way to improve students' higher level thinking skills. These skills include synthesis, analysis, and evaluation, often perceived as the top categories in Bloom's taxonomy (Turner, 2010). One of the strongest arguments in favor of using peer reviews is that benefits extend to reviewers as well as reviewees. As recent research noted, "...writing a peer review involves cognitive processes that encourage deep learning” (Wessa \& De Rycker, 2010). At least four possible reasons have been suggested why peer review is effective: students complete assignments ahead of the due date; students review assignment directions a second time; 
students submit better work when they know peers will be reviewing; and students react better to peer comments than to teacher comments (Reiber, 2006). Further, as an active learning activity, peer review involves students to an extent that is not possible with traditional faculty feedback. This active element is cited as one possible reason for the popularity of peer review in the classroom (Turner, 2010).

The mechanics of classroom peer review are well-defined. Peer reviews are most often done using paper or by editing electronic documents. In addition, peer evaluation groups (Anewalt, 2005; Yuehchiu, 2006) and clicker peer review of presentations (Walker \& Barwell, 2009) have also been used. Most classroom peer review is blind, i.e., the reviewees do not know the identity of their reviewer. Sometimes, classroom peer review is double-blind, where the reviewers also do not know whose work they are reviewing. In terms of guidance provided to the peer reviewers by faculty, there are at least three approaches: (1) open-ended peer review, where the teacher provides little guidance for reviewers; (2) guided peer review, where the teacher provides a list of general questions to consider; and (3) directed peer review, where the teacher provides reviewers with a detailed checklist (Reiber, 2006). Alternatively, a workshop session could be used to train reviewers (Thio, 2005/2006). In any case, effective classroom peer reviews require the peers to have similar knowledge and training. When some students have a vastly different background, the peer review process itself can be challenged (Wang, 2002).

Peer review is often used as a way to improve student writing (Reiber, 2006). There is even specialized software available, including SWoRD (Nelson \& Schunn, 2009) and CPR (Walvoord, Hoefnagels, Gaffin, Chumchal, \& Long, 2008), specifically developed to facilitate peer review of writing. While an extensive body of literature is devoted to peer review of writing, peer review has been used less commonly in other areas. For example, peer review has been used to aid learning in a statistics course (Wessa \& De Rycker, 2010), to improve writing in a science course (Gerdeman, Russell, \& Worden, 2007), and to increase students' confidence in their ability to evaluate science reports in the media (Moran \& Van Hook, 2006).

Although peer review is used by Information Technology (IT) practitioners to catch errors early in the development cycle (Norton \& Schulman, 2010), it has not been used nearly as widely in IT classrooms as in writing classrooms. Within the IT field, peer review has been applied to evaluate and improve contributions when students take part in a software development project team (Anewalt, 2005; Gamble \& Davis, 2002), as well as to teach UML design (Turner, PerezQuinones, \& Edwards, 2007) and framework development in an advanced software engineering course (Zeid \& Elswidi, 2005). Some of the earliest IT-related peer review efforts involved code inspection (Hilburn, 1996). More recently, one study found that decomposition in particular benefits more from peer review than some other object oriented programming concepts (Turner, 2010). Another study found that participating in peer reviews of computing assignments resulted in better learning outcomes (Reily, Ludford Finnerty, \& Terveen, 2010). Overall, IT-related educational peer review experiences tend to focus on software development. However, cognitive development is also important. In an article on employing critical thinking in the Information Systems curriculum, Thomas, Davis, and Kazlauskas (2007) describe using anonymous peer review of both writing and programming assignments to help students develop high-order thinking skills.

\section{Study Context}

Two sections of the same introductory level course were being taught by the same professor in the same academic term, one section in the traditional classroom and one as an online section. Traditionally, this course included a peer review component. The challenge we faced was how to modify the peer review that we had been using effectively in the classroom to make it feasible for the online section as well. 


\section{The University and the Students}

The university involved is a large private institution located in a major Midwestern U.S. city. Enrollment exceeds 25,000 annually. Undergraduate credit hours make up about three-quarters of total enrollment, with Master's, JD, and $\mathrm{PhD}$ students accounting for the rest. Fifty-four percent of all students are women, and 29 percent are people of color. The average high school GPA is 3.5 out of 4.0, with 22 percent of entering undergraduates ranking in the top 10 percent of their high school class. Thirty-five percent of entering students are the first generation in their families to attend college. The university has two major campuses: a downtown campus that accounts for 44 percent of credit hours, and a neighborhood campus that accounts for 53 percent of credit hours. The two main campuses are located approximately 10 minutes apart by commuter train. Five percent of total credit hours currently are generated by online courses. The university's administration is actively encouraging the development of additional undergraduate online courses.

Students in both sections of the course studied here were traditional United States university age, ranging from 18 to 26. Year in school ranged from freshman to senior, with a majority of upperclassmen. Both sections studied here were fully enrolled, the classroom section with 30 students and the online section with 40 students. The online section closed first because it was the only online section available. Because students who have earned more credit hours register first, the online only section was comprised of somewhat more experienced students, as shown in Table 1.

Table 1. Comparison of classroom and online classes by year in school

\begin{tabular}{|c|c|c|}
\hline & CLASSROOM & ONLINE \\
\hline Seniors (4 $4^{\text {th }}$ year $)$ & 10 & 21 \\
\hline Juniors ( $3^{\text {rd }}$ year $)$ & 12 & 10 \\
\hline Sophomores $\left(2^{\text {nd }}\right.$ year $)$ & 6 & 3 \\
\hline Freshmen $\left(1^{\text {st }}\right.$ year $)$ & 1 & 0 \\
\hline
\end{tabular}

As shown in Table 2, 59 percent of the classroom students came from the College of Commerce, 24 percent from the College of Communication, and 17 percent from the College of Liberal Arts and Sciences. On the other hand, in the online course, 32 percent came from Liberal Arts and Sciences, 29 percent from Commerce, and only 15 percent from Communication. These differences in home college are likely due to the physical location of the traditional class, very near the Commerce and Communication colleges and ten minutes away by commuter elevated train from the large College of Liberal Arts and Sciences.

Table 2. Comparison of classroom and online classes by student's home college

\begin{tabular}{|lcr|}
\hline & CLASSROOM & ONLINE \\
\hline Commerce & 17 & 10 \\
\hline Communication & 7 & 5 \\
\hline Liberal Arts and Sciences & 5 & 11 \\
\hline Miscellaneous & 0 & 8 \\
\hline
\end{tabular}

As noted earlier, the classes studied here began with 30 traditional classroom students and 40 online students. The classes ended with 29 traditional classroom students and 34 online students. 
This includes one student who switched from traditional to online and one who switched from online to traditional. The resulting drop rates were 3.3 percent for the traditional classroom and 15.0 percent for online students.

\section{The Course}

The course, entitled "Multimedia and the World Wide Web," meets three clock hours per week for ten weeks. It teaches non-IT majors the essentials of HTML coding, including embedding music, slideshows, and videos on web sites. It also meets university-wide liberal studies requirements for a Scientific Inquiry course. Detailed Learning Goals for the course are given in Appendix A. These focus on two major areas: designing and building web sites and the philosophy, practices, and procedures of science. Major student work in the course is shown in relation to major learning goals by Figure 1. The two major course deliverables are a professional career web site, completed by each individual student, and a study web site, where a group of students report in scientific format about the findings of a study they conduct. This study involves adhering to the principles of the scientific method while exploring some aspect of the use of information technology by college students. Each student group chooses its own specific topic for its study. In terms of course content, exactly the same material was presented to both groups by the same professor. Both groups received the same handouts. Lectures, using the same PowerPoint and handout files used in the classroom, were recorded digitally by the same professor and made available to the online students.

\section{Relevance and Significance of Peer Review to the Course}

An important part of scientific research, as with all research, is peer review. Peer review is critical at two stages in the scientific method: when results are submitted to journals or other outlets for possible publication, and after research becomes publically available. In addition, peer review can also be important earlier in the scientific process, as researchers are determining what problems to consider and what methods to use. Often at these stages, less formal peer review takes place with colleagues at conferences or even via email.

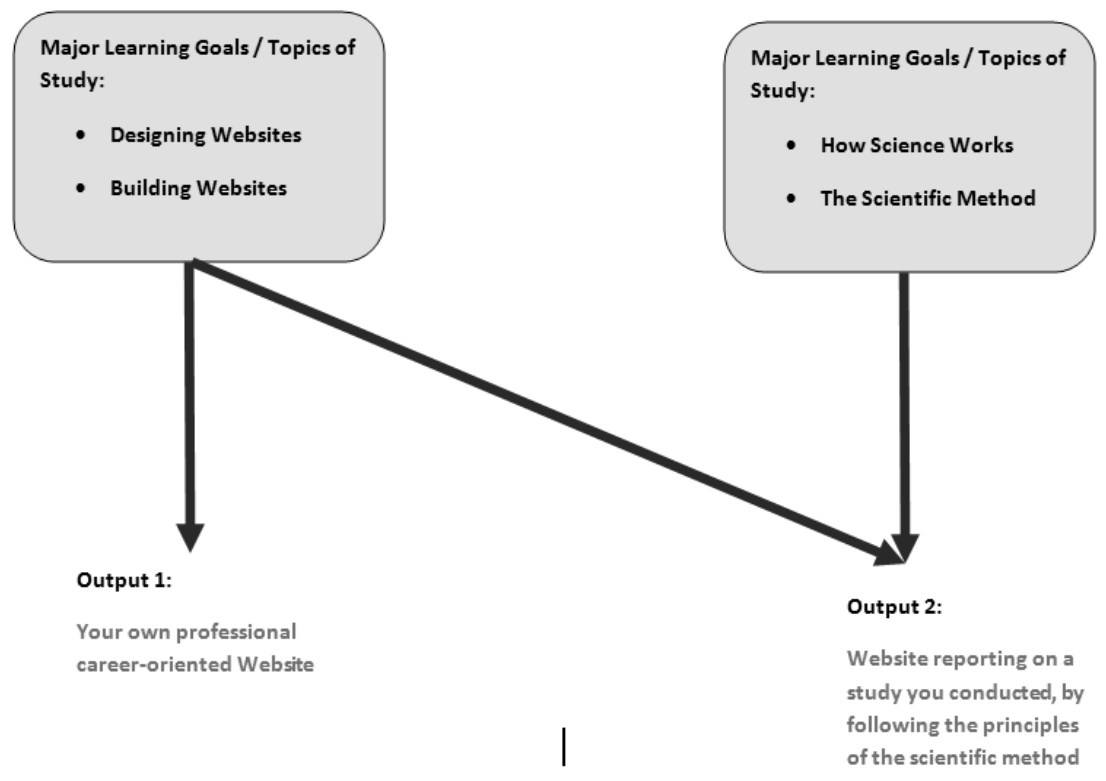

Figure 1. Course Learning Goals and Deliverables 
As students study the process of science in this course, they become aware, usually for the first time, of the importance and need for peer review in the sciences. Conducting the peer reviews themselves allows students to recognize how difficult and time-consuming quality peer reviewing can be. Further, through the peer review process, students are forced to examine in-depth others approaches to a problem, approaches that often differ from their own. Finally, employing peer reviews for the students' professional web sites allows the science material to inform the technical (non-science) portion of the course, thus encouraging students to apply learning from one context to another. This ability to transfer knowledge and skills to new domains is a hallmark of true learning and an indication that students have gone beyond memorizing to developing an internal understanding, incorporated within their own personal knowledge frameworks.

\section{Peer Review in the Traditional Classroom}

For several years, blind peer reviews were conducted in traditional classroom sections of this course. This involved taking students into a lab, giving them the URLs of peer sites to be reviewed, and asking them to complete a web site review form for each of three or four sites. A copy of this form is included in Appendix B and may be useful to other faculty interested in either conducting peer reviews or using a very specific grading rubric for student web sites. The form consists of roughly sixty questions on requirements; navigation, usability and accessibility; use of space, image, color, and multimedia; clarity and style of coding; browser compatibility; and more. While the review form used in this course is far more detailed than many academic peer reviews, its level of detail was necessary given that this was students' first reviewing experience and they needed specific guidance on what to consider. This detailed approach is consistent with Rieber's view that a specific checklist is advantageous because it ensures that the same criteria is used for all reviews, that less knowledgeable students will be able to execute a review, and that reviews are thorough (2006).

With two classes of students, the ideal way to run blind peer reviews is to have students in each section review students in the other section. Since we are part of a very large university and assign reviewers randomly, this leads to very few conflicts of interest. Students who do have more than a passing acquaintance with the peers assigned to them for review are asked to declare this and then are assigned alternative peers to review. Students readily comply with the request to declare their relationships, since their own grades on this major assignment depend on both the quality of their web site as determined by their peers' reviews and the quality of their own reviews. In general, each student is asked to complete three to four reviews, something that is easily accomplished within an hour and a half, even for the slowest of students.

Traditionally, the peer review form was printed on paper and filled in by hand during class, so that in a later classroom session, students easily could be handed back their peers' anonymous comments and given the opportunity to reflect and comment upon the reviews. Using paper forms, it was relatively easy to cover over the name of the peer reviewer with a simple fold of the paper, securely taped shut. However, the introduction of an online section of the course meant that hard-copy reviews were no longer feasible--we needed a new approach to blind peer review of web sites. Initially, we actively sought software designed for this purpose. However, we found little peer review software available for classroom use, with most of what was available either focused on writing assignment review (Nelson \& Schunn, 2009) or written by a particular school for its own use (Reily, et al., 2010) or both (Walvoord, et al., 2008).

\section{Requirements for the Online Peer Review Process}

We wanted the new peer review process to allow us to continue to have one class of students review the work of another. This was complicated by the fact that with one online and one traditional classroom section, we needed to find a solution that would work for both. We also needed 
that solution to provide an easy way to return peer reviews, minus any information identifying the reviewer, to the reviewee. Further, we wanted to keep the ability for students to declare their prior relationship with an assigned reviewee and be assigned a new peer to review. Finally, we wanted an easy way to sort peer reviews, not just by reviewee, but also by reviewer, since both were necessary to maintain the principle of grading the web site projects based on the quality of the web site as determined by peer reviews, as well as the quality of the web site author's peer reviewing of others. As faculty, we also wanted a solution that was available to us without having to request special funding or software development. Above all, we wanted a solution that was simple.

\section{Method of Identifying a Solution}

First we considered simply having all students complete the paper review forms electronically. By using RTF files for the reviews, students could complete them electronically regardless of whether they used a Mac or a PC, and all the reviews could be submitted using our university's Learning Management System, Blackboard. The problem we immediately saw with this approach was that removing identifying information from each of these files would be time consuming, since many of the students, regardless of any directions they were given, would use programs like Microsoft Office that automatically embed author information in their documents. Further, the Learning Management System automatically would name all the files to include the author's name, an action that was clearly undesirable for peer reviews and tedious for us to undo. To make matters worse, once we had removed identifying information, we could no longer use the same files to re-sort by the review's authors. This meant that we would be working with two sets of two hundred-plus files (3-4 reviews for each of sixty-plus students). One set we would sort by review author and the other we would sort by web site author for returning to the students. Further, returning the files to the students would mean emailing three or four peer review files to each of the sixty-plus students remaining in the class, taking care not to email anyone someone else's reviews. Clearly moving directly from paper to computer with minimal changes was not a simple solution. However, we were not dismayed.

On the face of it, we still saw this as a simple problem. After all, computers are ideal for inputting and storing data, manipulating data as needed to replace some data or to remove identifying information, and sorting and re-sorting data. Surely we quickly could devise a readily available, easy to use, and minimal cost computerized solution to our peer review dilemma. We knew now that we needed some sort of online form into which students could place their peer review data. We thought of constructing a web site for this purpose. However, this would be too timeconsuming, since the review includes over sixty questions, each of which contains optional comments. Further, any web site would require a backend database to store the entered reviews, significantly complicating its construction. Clearly this approach did not meet our desire for a quick and easy solution.

Since at this point we knew we needed our own online form and we knew designing and building our own web site for this purpose was not feasible, we turned to considering using an online survey site for our peer reviews. Students in the course were already familiar with surveymonkey.com, since we were using this site for another assignment in the course. However, surveymonkey limited free surveys to just ten questions, clearly insufficient for our in-depth reviews. We considered other free online survey sites, including zoomerang.com and freeonlinesurvey.com, but found similar restrictions on the number of questions and/or the number of responses. Eventually, we ferreted out kwiksurveys.com, a free online survey site that does not limit either the number of questions or the number of responses. Unlike other sites, kwiksurveys does not provide extensive statistical analysis as an option, but this was not one of our requirements. Kwiksurveys also had a number of other features that we found attractive. It allowed us 
to set a password so that non-students could not enter junk into our data file, and it allowed us to easily open and close the survey for use. It also provided an ability to download an Excel spreadsheet of the data entered by "survey takers." Finally, it allowed us to ask the peer reviewers to award each web site 1 to 5 stars, a nice attribute that students related well with. Figure 2 shows how a small portion of our peer review looked on the kwiksurveys site.

Kwiksurveys provided an easily downloadable spreadsheet of the data. However, we found that

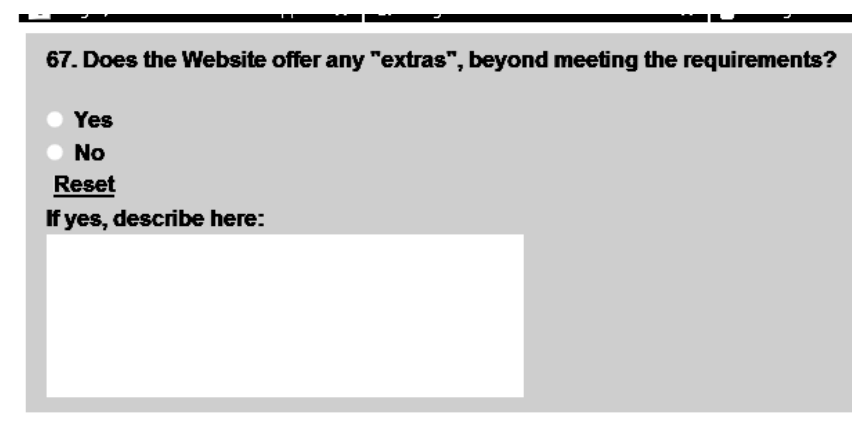

68. Overall how would you rate this Website?

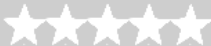

Reset

Please explain.

Figure 2. Sample of how questions appear to students in Kwiksurveys we had to reformat the spreadsheet, not just to remove items like start and stop time and session number, but also to make it easier for students to review their peer review data once we sent it to them. This involved setting up a heading row that contained the wording of each question, as well as highlighting key rows, such as the number of stars given to their site, and whether or not their site was nominated for "best in class." A sample of just a small portion of the kwiksurvey data as it was downloaded is shown in Figure 3. The particular section includes the summative comments column. Other comments were sprinkled through the spreadsheet as students had the option of entering comments for every question.

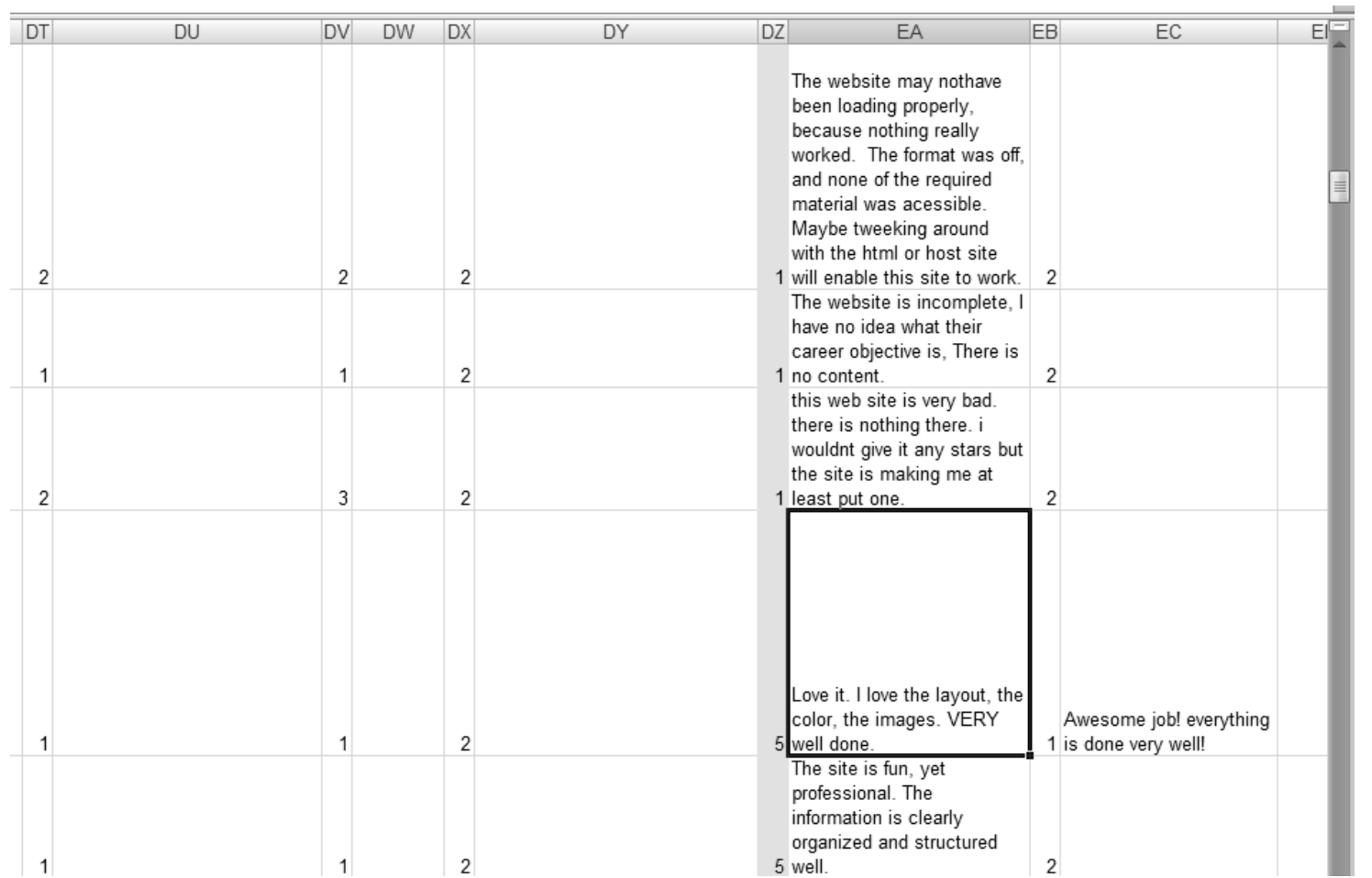

Figure 3. Sample peer review results (for 2 different students) as downloaded from kwiksurveys 
In addition to formatting the spreadsheet data for easier student perusal, we also found we had to clean the data, again something that was not necessary when using paper in a traditional classroom. For example, some students did not read carefully and put the name of the person they were reviewing where their name should have been, and vice versa. This never happened in the classroom, but then in the classroom we had always given formal directions, holding up a sample form, and indicated where to place each name. The very nature of computer usage introduced errors not seen previously in a paper system and, thus, required added time and effort to handle. Further, even after the data was cleaned, we were not finished. We needed to find a way to return to students only those peer reviews that related to their web site. Ultimately, the easiest way was to use a free program named Cutepdf writer. Like several other similar programs, Cutepdf acts as a pseudo-printer, allowing you to create a pdf file by requesting a print to Cutepdf. In our case, we opened the cleaned spreadsheet, sorted it by the name of the person whose site was being reviewed, selected the title rows along with the three or four lines representing all the peer reviews for this person, and then wrote out a pdf file of those rows, naming the file for the person whose site was reviewed. We then deleted the rows for this person and went on to repeat the process for the next person. Once all sixty-plus files were created, one for each student peer reviewed, we used our university's Learning Management System, in this case Blackboard, to send a single email to each student with their peer review pdf attached. This process was carried out one email at a time.

\section{Analysis of Results}

The paper system worked well in the traditional classroom, but could not be applied to an online course. The online system we developed solved this problem. However, online comments were not as extensive as paper comments, a fact that supported earlier research (Turner et al., 2007). Further, online peer review also involved much more faculty time and effort, as shown in Table 3. For the sake of simplicity in interpreting the relative complexity of the two columns, two class sections with a total of 60 students, each doing just 3 reviews is assumed.

\section{Table 3. Comparison of paper and electronic peer review systems}

Paper peer review system Online peer review system

\begin{tabular}{|c|c|c|}
\hline $\begin{array}{l}\text { Step 1: } \\
\text { Create the } \\
\text { grading ru- } \\
\text { bric }\end{array}$ & $\begin{array}{l}\text { Create grading rubric to distribute to } \\
\text { students as they work on their own web } \\
\text { site }\end{array}$ & $\begin{array}{l}\text { Create grading rubric to distribute to } \\
\text { students as they work on their own web } \\
\text { site }\end{array}$ \\
\hline $\begin{array}{l}\text { Step 2: } \\
\text { Create the } \\
\text { peer review } \\
\text { forms }\end{array}$ & $\begin{array}{l}\text { Produce } 180 \text { photocopies of the re- } \\
\text { views. } \\
\text { Produce } 180 \text { coversheets for students to } \\
\text { enter their name and their peer's name. } \\
\text { Staple a coversheet to the top of each } \\
\text { peer review form. }\end{array}$ & $\begin{array}{l}\text { Sign up for an online survey generator } \\
\text { Key all requirements on grading rubric } \\
\text { into the survey generator as questions } \\
\text { Set survey opening and closing dates } \\
\text { Set survey password }\end{array}$ \\
\hline
\end{tabular}


Paper peer review system

Step 3: Assign students to do specific peer reviews

Step 4: Respond to potential conflicts of interest by reviewers

Step 5: Collect data

Step 6; Handle late peer reviews

\section{Step 7:}

Prepare reviews for distribution to the reviewed students slips of paper class ceive the paper results. read and responded to during class.
Create a spreadsheet with names of assigned people

Cut up spreadsheet into strips and distribute during class

Online peer review system

Create a spreadsheet with names of assigned people (same)

Write an email with detailed directions on when and how to do the peer reviews online

Send the email, one at a time, once to each of 60 students, copying and pasting in the names of unique peers to be reviewed by each student. Doublecheck throughout this process to ensure that every student receives the correct reviews.

Since peer reviews are being conducted in a lab, anyone with a conflict comes forward and the professor switches their Professor assigns an alternate to the person with the conflict, but must also keep track of the people who are switching reviews so that each student ends up with the proper number of reviews.

Students hand in peer review packets in Students have several days to complete their peer reviews. At the end of this time, the system cuts them off so that the professor can begin preparing the data to return results to reviewed students.

A student can turn in a peer review very late and yet their reviewed peer can re-

Late reviews are difficult or impossible to add into the review process, depending on when they are received. Significant numbers of late reviews are a substantial problem.

Fold each cover sheet once to obscure Download spreadsheet from survey site. the name of the reviewer and tape sheet securely shut. This is sufficient to protect reviewer identify since reviews are

Sort papers by class section and name of person whose site is reviewed.

Clean data, correcting errors like name reversal and removing unneeded columns.

Prepare meaningful headings to help students interpret the results.

Sort by person whose site is being reviewed.

Save file before removing column holding name of reviewer

One at a time, create a separate pdf file for each student containing only their reviews. 
Paper peer review system

Step 8: Allow students to respond to peers' reviews of their sites

Step 9: Assign tentative grade to web sites

Step 10:

Assign interim grade to quality of reviews

Step 11: Generate a final grade on this project for each student forms themselves. peer reviews at end of class. being reviewed. and peer reviews. review. quality of reviews. grade for each student
Online peer review system

Hand back reviews during class session.

Ask students to respond to reviews at the appropriate spot on the review

Collect forms with student responses to

Sort review bundles by name of person

Look up each student web site online and compare with both grading rubric

Assign student a tentative grade Make notes on peer review pages of strengths of weaknesses of each peer

Take apart review bundles and resort them by the name of the reviewer.

Processing one reviewer at a time, look at comments made in the prior step about the quality of each review.

Assign interim grade for each student's

Merge the tentative web site grade from Step 9 with the interim review grade from step 10 to generate a final web site
Compose an email telling students how to respond to their peer reviews.

One at a time, email each of the $60 \mathrm{stu}-$ dents, attaching a file with only the peer reviews of that student's web site.

Double-check throughout this process to protect each student's privacy.

Set up a special email folder to hold responses to reviews

Respond to each emailed response to let the student know it was received

File each email response in the special folder set up for that purpose (autodirecting emails to this folder does not work since students do not reliably follow directions about email subjects).

Using spreadsheet already sorted by name of person being reviewed, look up each student web site online and compare the site with peer reviews, any emailed responses to those peer reviews, and the grading rubric.

Assign student a tentative grade

Make notes on the spreadsheet regarding the strengths and weaknesses of each peer review.

Resort spreadsheet by the name of the reviewer.

Inspect each person's reviews for quality, looking at comments made in the prior step.

Assign an interim grade for each student's quality of reviews done.

Merge the tentative web site grade from Step 9 with the interim review grade from step 10 to generate a final web site grade for each student

Clearly all except the first step in the eleven-step process, creating the grading rubric, required more time and effort for an online class than for a traditional class. Once we had developed the process charted in Table 3, we were able to analyze the table and recognize areas of particular increased complexity for online classes. This led to the development of Figure 4. Figure 4 shows the process as a whole, highlighting in teardrops those four steps that we found required the most 
added complexity in an online environment. The four steps we highlight with teardrops in Figure 4 form the basis for much of the discussion that follows.

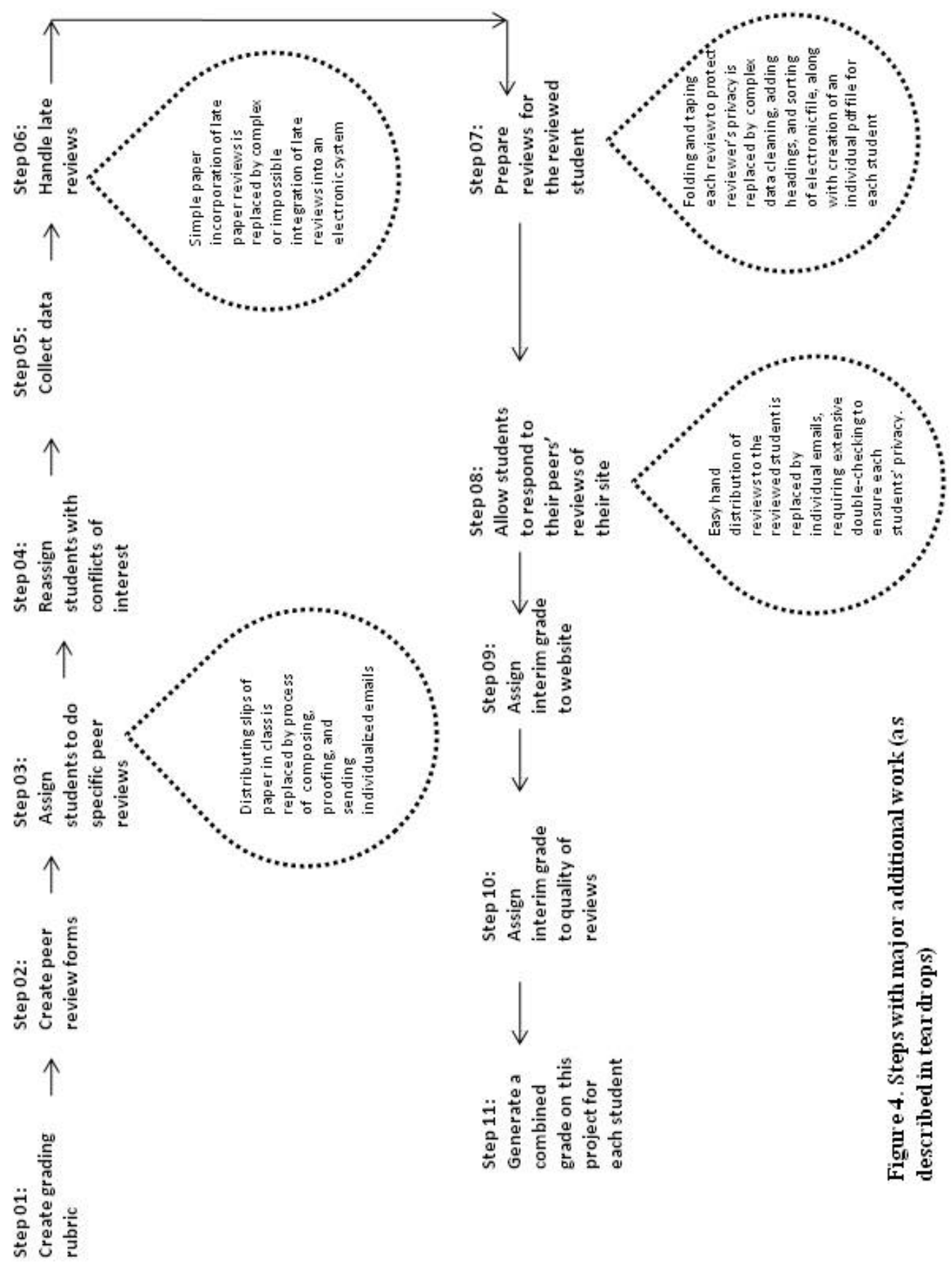




\section{Discussion}

When a paper approach to peer review in the traditional classroom is compared with an electronic approach for an online course, there are four major areas, shown by the teardrops in Figure 4, where the online peer review process is notably more complex for the professor. Three of these are ripe for software development. First, assigning students to do reviews can be done much more simply in person than by sending individual personalized emails. However, software could be developed relatively easily to smooth this email process. Second, distributing peer reviews back to the reviewees electronically is a complex process. Although developing software to take on this task would not be a minor endeavor, it could be done. Third, allowing reviewees to comment upon their reviews electronically is also a complex process that could benefit from similarly non-trivial computerization. Thus three of the four largest problems involved in online peer review could be addressed through the development of specialized software. The fourth problem is not feasibly addressed by software. While late peer reviews can be handled relatively easily in person, any electronic system will require having a firm cutoff date after which reviews simply cannot be accepted. While the late reviewer does not deserve our sympathy, the reviewee who does not receive the benefit of that late review does. Although all our students were given full directions well in advance and all students were sent reminders, one student still completed her peer reviews too late to be included with the survey data, instead emailing them to the professor in the form of $\mathrm{rtf}$ files of the original grading rubric, with her comments interlaced. Clearly there was no easy way to merge this data in with the other online reviews, whereas if we had been working with paper, we would have been able to let those reviewed see the results easily, by simply including a few late sheets. We did email students these late reviews done of their sites. However, this solution obviously does not scale the way it would when working with paper. This is a serious consideration in part because the problem of tardiness is much greater with online peer review. We had to set a cutoff date after which the survey link disappeared, so that we would have time to download the data into a spreadsheet, manipulate it, sort it, create the individual pdf files, and email those to the reviewees. This setting of a firm deadline with no acceptance of any late work resulted in three people who received no peer reviews at all. Sadly, all three of these were students who had worked hard to do in-depth reviews of the peers assigned to them.

We also uncovered one more minor issue worth noting. Without paper to sort and re-sort, it was more difficult to arrive at a combined grade for both the quality of the web site as determined by the peers and the quality of the peer reviews done by the site's author. We would seriously consider breaking these two criteria into two separate grades in the future. However, we are concerned that if we grade the work and the peer reviews separately and the peer review grade is not given substantial enough weight, students may be tempted not to declare their relationships and instead to provide friends with favorable reviews. Thus, if we do split the grade into two parts, we will need to ensure that the grade on the submitted peer reviews is a significant enough portion of the final grade to discourage students from using their peer reviews to "help" friends.

\section{Conclusions}

For instructors considering implementing peer review in an online course, our major recommendation is to identify and define your process in advance of the start of the course. If you are going to use an online survey site for data collection, as we did, then experiment with it, making sure it allows you to enter the number and type of questions you want, that it supports the number of students you will have in the course, and that it gives you results in a useable format that will require you to do a minimum of clean-up before sending reviews to reviewees. Since late reviews are virtually impossible to process in an online course, try to allow an extra buffer of time after the peer review due date before you begin processing the reviews. Not to do so is to rob students 
of reviews because their reviewers were tardy. Finally, plan to do extra communicating with your online students during the peer review process. You will want to send reminders about both the importance of completing the reviews on-time and the need for overcoming the human urge to simply rush through the checkboxes, and instead make substantial, thoughtful comments.

From an educational perspective, there were some observed differences between the traditional and online classes. Peer-review comments were briefer online than on-paper. This could be an inherent result of the two different methods or it could be a result of the differences in the two student populations described earlier. Grades were also notably lower in the online course, but we are inclined to believe that this was primarily due to the online nature of the course itself, which requires greater student motivation and self-scheduling. We also believe that the lower grades and briefer comments may be due at least in part to the reasons online students cited for taking this online course (difficulty scheduling, time pressures, need to cram in an extra course, and the like). While we were able to hold instructor constant in this study by having the same instructor in both the online and traditional sections of the course, we did have substantial dissimilarities in the student populations and are therefore hesitant to draw substantive conclusions about the educational differences in the two approaches. We leave this area for a future study.

Clearly, peer reviews can be conducted within online classes. However, the electronic process is far more complex than it is in a traditional classroom using paper forms for feedback. This is due in part to the fact that minor procedural steps that are easily made both unambiguous and obligatory in a classroom become far more difficult to implement online. In addition, since specific peer review software is seldom available, the need to use a variety of software products, each of which was originally designed for other purposes, adds substantially to the intricacy of the undertaking. This problem can be exacerbated in situations where administrators increase online class sizes in the mistaken belief that teaching online requires less of the professor's time and/or effort. All this is not to say, however, that peer reviews are not worth doing in an online course. The literature cited earlier makes many compelling arguments in favor of peer reviews. Peer review benefits both the reviewer and the reviewee by involving them in active learning and focusing on higher order learning involving synthesis, analysis, and evaluation. The issue then is not whether peer reviews are worthwhile, but whether they are worth the effort for faculty teaching online courses. To answer this, we turn to an elder statesman. Abraham Lincoln once said, "The probability that we may fall in the struggle ought not to deter us from the support of a cause we believe to be just" (Lincoln, 1839). To paraphrase Lincoln for the situation presented here, we would say that the probability that a mission will be time consuming ought not to deter us from implementing a process that we know will benefit our students. That said, we also recognize that for most faculty peer review for online courses will not be a reality until effective and efficient supporting software becomes widely available. That software may be developed as enhancements to one of the peer review programs currently available for writing-centric courses or as an enhancement to a journal or conference peer review system. Alternatively, and perhaps most likely, it may be developed from scratch. Regardless, we are hopeful that the description of the needed features and functionality detailed in this paper will form a basis for the requirements definition for a new peer review software package flexible enough to be used across disciplines and with both traditional and online classes. 


\section{References}

Anewalt, K. (2005). Using peer review as a vehicle for communication skill development and active learning. Journal of Computing Sciences in Colleges, 21(2), 148-155.

Gamble, R. F., \& Davis, L. A. (2002). A framework for interaction in software development training. Journal of Information Technology Education, 1(4), 223-232. Retrieved from http://www.jite.org/documents/Vol1/v1n4p223-232.pdf

Gerdeman, R. D., Russell, A. A., \& Worden, K. J. (2007). Web-based student writing and reviewing in a large biology lecture course. Journal of College Science Teaching, 36(5), 46-52.

Hilburn, T. B. (1996). Inspections of format specifications. SIGCSE '96 Proceedings, 150-154.

Lincoln, A. (1839). Speech on the Sub-Treasury. Collected Works of Abraham Lincoln, Volume 1, 160-179.

Moran, T., \& Van Hook, S. J. (2006). Using student peer review of experiment reports in an undergraduate physics class. Journal of College Science Teaching, 36(1), 45-49.

Nelson, M. M., \& Schunn, C. D. (2009). The nature of feedback: How different types of peer feedback affect writing performance. Instructional Science, 37(4), 375-401.

Norton, D., \& Schulman, J. (2010). Seven best practices for your agile software factory. Gartner Research 10. DOI: G00173140.

Reiber, L. J. (2006). Using peer review to improve student writing in business courses. Journal of Education for Business, 81(6), 322-326.

Reily, K., Ludford Finnerty, P., \& Terveen, L. (2010). Two peers are better than One: Aggregating peer reviews for computing assignments is surprisingly accurate. GROUP '09 Proceedings of the ACM 2009 International Conference on Supporting Group Work, 115-124.

Thio, L-A. (2005/2006). Facilitating independent inquiry, critical thinking and writing: An integrated teaching methodology aplied in human rights education. International Journal of Learning, 12(8), 107114.

Thomas, T., Davis, T., \& Kazlauskas, A. (2007). Embedding critical thinking in IS curricula. Journal of Information Technology Education, 6, 327-346. Retrieved from http://www.jite.org/documents/Vol6/JITEv6p327-346Thomas253.pdf

Turner, S. A. (2010). Peer review in CS2: Conceptual learning. SIGCSE '10 Proceedings of the 41st ACM technical symposium on Computer Science Education, 214-220.

Turner, S. A., Perez-Quinones, M. A., \& Edwards, S. H. (2007). Effect of interface style in peer review comments for UML designs. Journal of Computing Sciences in Colleges, 22(3), 331-335.

Walker, R., \& Barwell, G. (2009). Click or clique? Using educational technology to address students' anxieties about peer evaluation. International Journal for the Scholarship of Teaching and Learning, $3(1), 1-20$.

Walvoord, M. E., Hoefnagels, M. H., Gaffin, D. D., Chumchal, M. M., \& Long, D. A. (2008). An analysis of calibrated peer review (CPR) in a science lecture classroom. Journal of College Science Teaching, 37(4), 66-73.

Wang, L. (2002). Chinese students' perceptions of the practice of peer review in an integrated class at the university level. TESL Reporter, 42(2), 35-56.

Wessa, P., \& De Rycker, A. (2010). Reviewing peer reviews - A rule-based approach. International Conference on E-Learning, 408-418.

Yuehchiu, F. (2006). The effects of peer review in EFL college composition classes. International Journal of Learning, 13(5), 147-152.

Zeid, A., \& Elswidi, M. (2005). Using peer reviews in teaching fraamework development. Proceedings of the 27th International Conference on Software Engineering, 627-628. 


\section{Appendix A. Course Learning Goals (page 1 of 2)}

\section{Science Related Learning Goals}

This course is certified by the university as meeting its Scientific Inquiry domain requirements. Below are listed the learning goals and outcomes for the Science Inquiry Domain. Each goal is listed followed by learning outcomes associated with the goal. Most of this document conforms to the National Science Education Standards.

Students will understand the major principles guiding modern scientific thought. Students will demonstrate a mastery of the science content knowledge of their SID courses.

Students will know that science, technology, and math serve as mechanisms for inquiry into the nature of the universe. Students will:

a. identify questions that can be answered through scientific investigations

b. design and conduct a scientific investigation to test a scientific hypothesis

c. use appropriate tools and techniques to gather, analyze, and interpret data to support or refute a scientific hypothesis

d. develop descriptions, explanations, predictions, and models using evidence

e. describe relationships between evidence and explanations using critical and logical thinking

f. recognize and analyze alternative explanations and predictions

g. communicate scientific procedures and explanations

h. use mathematics in all aspects of scientific inquiry

Students will understand and appreciate the interrelationships among science, technology and math. Students will:

a. use technology and mathematics to identify a problem or design a solution to a problem

b. give examples of how science and technology inform and influence each other

Students will understand and appreciate the role of science in society and in their lives. Students will:

a. provide examples of how science and technology impact our lives, and how social needs and concerns impact our development of technology and scientific investigation

b. develop positive attitudes towards science, technology, and mathematics

c. establish an ongoing experiential/service-learning interest in science, technology, and mathematics

Students will understand the nature of science, technology, and mathematics. Students will:

a. provide examples of the abuse of science, including the representation of unfalsifiable claims as science and other forms of pseudoscience

b. explain the strengths and limits of scientific inquiry

c. explain the difference between evidence and inference, and the provisional nature of scientific explanations by providing examples of how our understanding of the workings of the world has changed in the past

d. explain the difference between probability and certainty, and describe what is meant by uncertainty in the context of science, technology, and mathematics 


\section{Appendix A. Course Learning Goals (page 2 of 2) \\ Writing Expectations}

Writing is integral for communicating ideas and progress in science, mathematics and technology. The form of writing in these disciplines is different from most other fields and includes, for example, mathematical equations, computer code, figures and graphs, lab reports and journals. Courses in the SI domain must include a writing component where that component takes on the form appropriate for that course (e.g., lab reports, technical reports, etc.)

\section{Technology-Related Learning Goals}

- Understand how the Internet differs from the World Wide Web.

- Understand the difference between client and server computers in terms of the Web.

- Understand the distinct roles of ISPs and Web hosts and the processes involved in selecting them both.

- Understand the structure of Domain Names.

- Understand the distinction between local computer and Web host, and be able to accurately identify the location of files (its folder and its local or remote status).

- Be able to build simple XHTML pages that employ links, images, lists, and a one-row table for a menu

- Be able to edit images appropriately for the Web (primarily resizing and cropping)

- Understand the basic copyright and legal issues relating to the Web, particularly to images, music, and multi-media formats, and to follow these principles on one's own Websites.

- Understand the benefits of using CSS.

- Understand the principles of and be able to evaluate a Website for usability, navigability, accessibility, and content quality.

- Be able to build a personal Website that presents a professional image to potential employers.

- Be able to generate pdf type files and incorporate pdfs into a Website.

- Be able to incorporate simple multimedia aspects, including slide shows, sound, and video into a Website.

\section{Brief summary of technology topics that will not be covered}

- In-depth understanding of CSS, including using CSS for placement on the webpage

- JavaScript

- Nested tables

- In-depth understanding of XHTML and advanced XHTML features, including forms, floating

- Programming concepts, including abstraction, functions, algorithms, Event Driven Programming, conditional execution, and random variables

- Graphics, beyond a very elementary level, any animation

- Server-side programming

- Database access, input and output, including form input 


\section{Appendix B. Peer Review Form (page 1 of 2)}

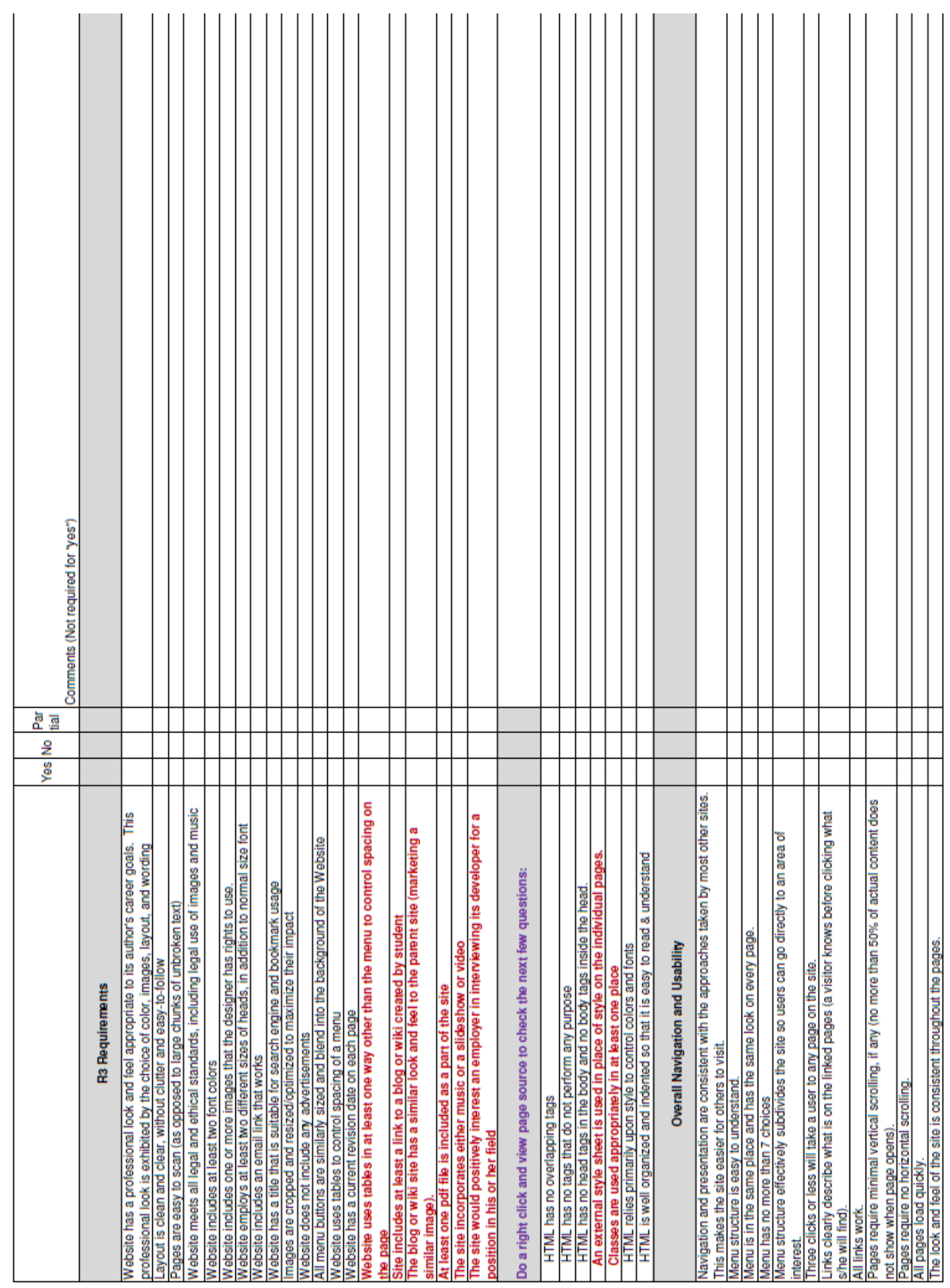




\section{Appendix B. Peer Review Form (page 2 of 2)}

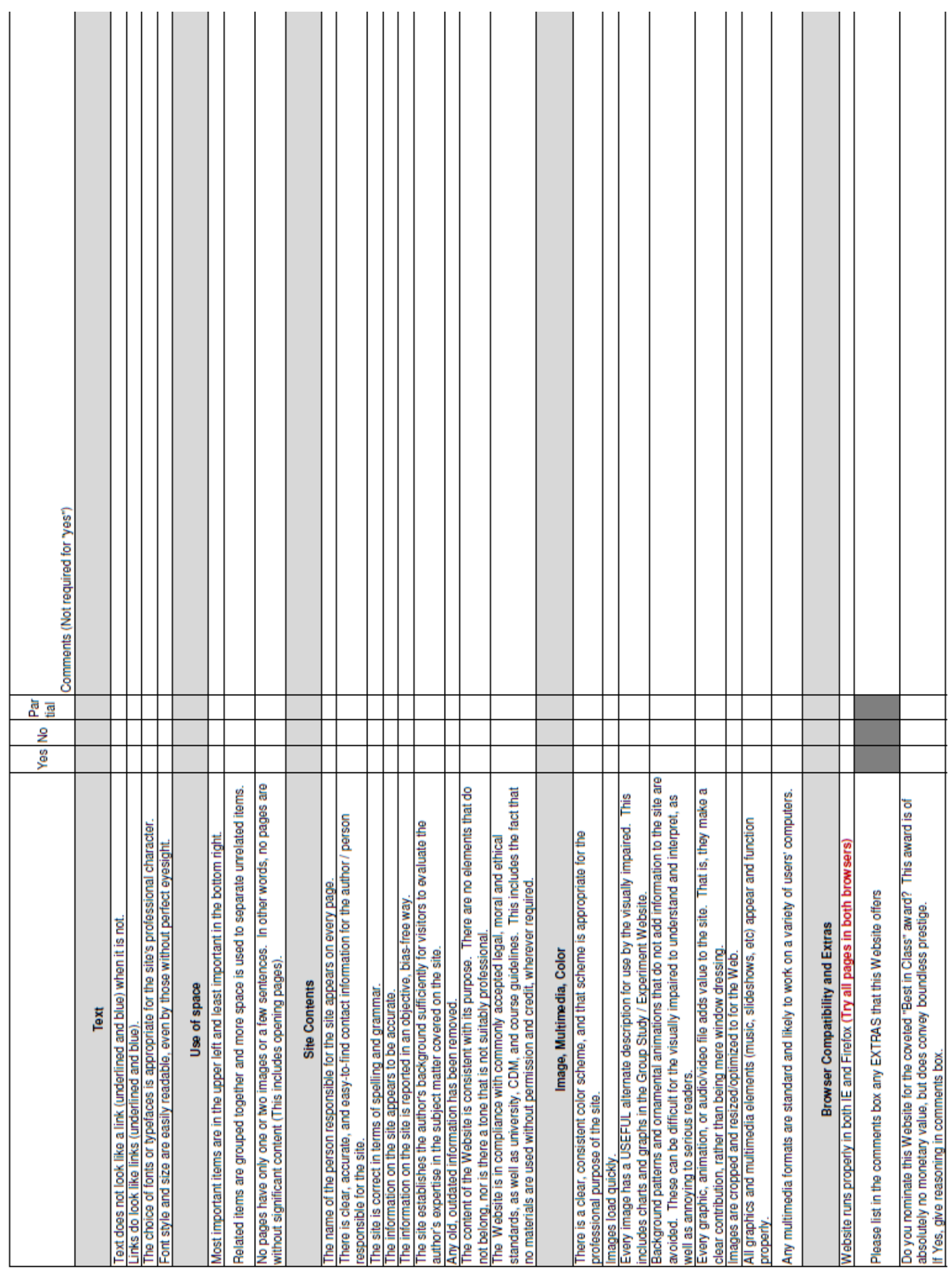




\section{Biographies}

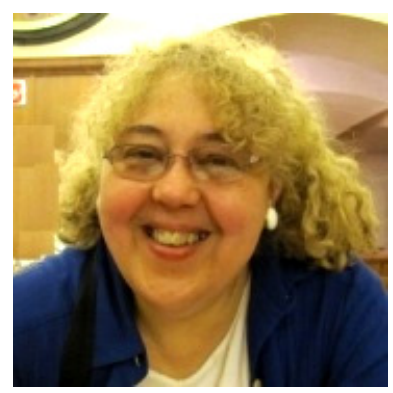

Linda V. Knight, $\mathrm{PhD}$, teaches and conducts research in the area of Information Technology strategy and development. Editor-in-Chief of the Journal of Information Technology Education, she is also former Associate Editor of the Information Resources Management Journal, as well as Past President and Fellow of the Society for the Advancement of Information Systems, an affiliate of MBAA International. She has served on the Editorial Advisory Board of the Journal of Cases on Information Technology, and as a member of the Information Resources Management Association Executive Council. A Fellow of the Informing Science Institute, she also served 5 years on MBAA International's Executive Board, including a term as President. An entrepreneur and IT consultant, she has held industry positions in IT management and quality assurance management, and served over seven years as Associate Dean. In addition to a Ph.D. from DePaul University, she holds an MBA and a bachelor's degree in mathematics, both from Dominican University.

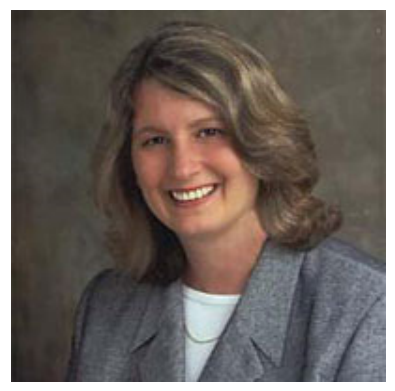

Theresa A. Steinbach holds a PhD in Computer Science from DePaul University. She also holds a MS in Information Systems, MBA in Quantitative Economics and a BA in Mathematics. Her primary research interests are IT education, system development methodology, project management and IT ethics. She is the faculty advisor for the Digital Divas and ACM-w student organizations which are networking and support communities for CDM women. She currently is a coinvestigator for an NSF-funded grant to mentor undergraduate students. Terry is the representative of DePaul University to the National Center for Women \& Information Technology (NCWIT). She serves on the Executive Committee of NCWIT's Academic Alliance as well as chairs the NCWIT's Aspirations in Computing Award competition - Illinois region. Prior to teaching full-time for DePaul CDM, Terry owned her own consulting firm that specialized in maximizing technology for business growth and profits. Her client base included representatives from the banking and nursing home industries, accounting firms, mortgage bankers, park districts and other municipal entities, and small and midsize retail businesses. 